\title{
Reseña de Adillo Rufo, Sergio, Catálogo de representaciones del teatro de Calderón de la Barca en España (1715-2015), Madrid, Fundación Universitaria Española, 2017, 667 pp. ISBN 9788473928823
}

\section{Fernando Rodríguez-Gallego}

http://orcid.org/0000-0002-6539-0447

Universitat de les Illes Balears / Institut d'Estudis Hispànics en la Modernitat ESPAÑA

f.rodriguez-gallego@uib.cat

[Hipogrifo, (issn: 2328-1308), 7.2, 2019, pp. 947-953]

Recibido: 23-10-2019 / Aceptado: 30-10-2019

DOl: http://dx.doi.org/10.13035/H.2019.07.02.71

El título de la presente monografía de Sergio Adillo, extraída de su tesis de doctorado, no hace justicia a su contenido, pues, aunque, en efecto, ofrece lo que en él se anuncia, quiere ir más allá, y aportar un análisis de la presencia de Calderón en las tablas españolas a partir de tres objetivos que el mismo autor enumera en p. 14: 1) «constatar la presencia y/o la ausencia del teatro de Calderón en nuestros escenarios y dar cuenta de los cambios en el repertorio de sus obras representadas durante estos tres siglos con el fin de establecer ciertas tendencias que nos permitan delimitar cortes diacrónicos en la evolución de su lugar en la cartelera española»; 2) «explicar qué factores (políticos, económicos, sociales, culturales, estéticos...) han intervenido en la presencia y/o la ausencia de su teatro sobre las tablas así como en la configuración de su voluble canon escénico»; 3) «concretar qué función ha jugado Calderón, como una de las cumbres de la dramaturgia universal, en la génesis de un hipotético campo teatral».

La búsqueda de estos tres objetivos a partir de la minuciosa exposición del catálogo resulta problemática, pues realmente solo el primero de ellos se puede estudiar, de manera directa, a partir de las fichas del catálogo en sí; los otros dos exigen la indagación en otras fuentes y son tratados de manera acaso demasiado somera en este libro, por lo que quizá hubiesen tenido mejor encaje como obras separadas, 
para permitir un mayor ahondamiento en el primero de los objetivos, y así parece haberlo aplicado el mismo Adillo en otros trabajos ${ }^{1}$.

El libro se compone de tres partes fundamentales: una introducción de siete páginas (pp. 9-15) en la que se plantean las bases del trabajo; el grueso de la monografía, compuesto por cinco capítulos que recogen las fichas de las representaciones de obras de Calderón entre 1715 y 2015 divididas en diferentes segmentos temporales (pp. 17-590), y una conclusión de dieciséis páginas (pp. 591-606), todo ello acompañado de una impresionante bibliografía de 61 páginas en letra pequeña y en el enorme y poco manejable formato en el que sigue publicando la FUE. A su vez, cada uno de los capítulos repite un mismo esquema de introducción (de una o dos páginas), las fichas de los espectáculos en el período correspondiente (la mayor parte del capítulo) y una conclusión de entre tres y cinco páginas.

De la exposición de este contenido puede ya observarse cómo la consecución de los tres objetivos marcados se ve lastrada por las pocas páginas dedicadas al análisis, que, por ello, aunque siempre interesante, es muy sucinto, por lo que queda acaso un tanto deslucido frente a la ingente cantidad de información que proporcionan las fichas recopiladas por el autor.

La división en cinco capítulos se establece a partir de criterios cronológicos, y los cortes se introducen «en torno a varias fechas con valor simbólico» (p. 15), bien desde un punto de vista histórico-político, bien por algún acontecimiento cultural. Los segmentos temporales establecidos son 1715-1881 (cap. 1), 1881-1927 (cap. 2), 1927-1939 (cap. 3), 1939-1981 (cap. 4) y 1981-2015 (cap. 5). Como puede apreciarse, el capítulo 1 abarca 166 años, más de la mitad de los contemplados en la monografía, así como un porcentaje muy elevado de las representaciones totales de Calderón en esos 300 años, dada su frecuente presencia en los escenarios dieciochescos (las fichas de este capítulo ocupan nada menos que 250 páginas, y se trata de fichas mucho más breves que las de períodos posteriores, pues los datos conocidos sobre esas puestas en escena tienden a ser escasos). Sin embargo, el capítulo se presenta con una página y media de introducción, y termina con una conclusión de tres páginas, que contrastan, por ejemplo, con las cuatro del capítulo 3 (1927-1939) o las cinco del capítulo 5 (1981-2015), a pesar de que se refieren a períodos mucho más breves y recogen muchos menos espectáculos, de tal manera que, paradójicamente, a menor presencia de Calderón sobre las tablas, el análisis se hace más detenido.

Cabe preguntarse si no habría sido importante distinguir más cortes dentro del extensísimo capítulo primero, teniendo en cuenta la enorme cantidad de representaciones documentadas en él, por un lado, y lo heterogéneo del período abarcado, por otro. Pienso por ejemplo en el dominio ejercido por Calderón en los escenarios del XVIII, en la tensión que supuso someter sus obras a las drásticas refundiciones neoclásicas de finales del XVIII y principios del XIX, en la ocupación francesa, en el triunfo del Romanticismo tras la muerte de Fernando VII y el posterior predominio

1. En esta línea, Sergio Adillo acaba de ganar el IV Premio de Investigación José Monleón con su obra La resignificación de Calderón en la escena española reciente (1987-2018). 
de fórmulas más realistas, o en la liberalización del mercado del ocio impulsada en 1847, aspecto al que el propio Adillo concede gran importancia con respecto a la formación de un campo teatral (p. 592). Estos importantes cambios históricoculturales quizá habrían aconsejado introducir más subdivisiones, para observar las variaciones de la presencia de Calderón sobre las tablas con más detalle.

En todo caso, el protagonista indiscutible del libro son las fichas dedicadas a las diferentes representaciones de obras de Calderón documentadas y recopiladas por Adillo. Todas ellas siguen el mismo esquema: título de la función, compañía, funciones, elenco, equipo técnico y artístico, y un apartado en el que se recogen noticias sobre la función o críticas, si las hubiere o se conservaren. Debe tenerse en cuenta que las fichas se organizan por años naturales, de tal manera que, si una misma compañía representa una misma función en años sucesivos, existe una ficha del espectáculo para cada año. Por ejemplo, el montaje de La dama duende dirigido por José Luis Alonso para la CNTC cuenta con una ficha en 1990 y otra en 1991; lo único que varía en ellas es el apartado de las funciones, así como el de las críticas, aunque a veces también se repiten los fragmentos extractados del programa de mano, como sucede con los montajes de El médico de su honra de Teatro Corsario de 2012 (p. 547) y 2015 (p. 573).

Estas fichas van desde las muy sucintas de gran parte de los siglos XVIII y XIX, que muchas veces no recogen más que título, compañía y alguna función, de tal manera que una sola página puede contener hasta doce fichas (p. 94, por ejemplo), a las muy detalladas de los montajes más recientes, en particular los del capítulo 5 , que pueden ocupar más de una o dos páginas al incluir notas abundantes de los programas de mano, críticas de prensa y otros materiales como libros de memorias o artículos académicos. Pueden verse como ejemplo las completas fichas de algunos montajes polémicos, como el de Adolfo Marsillach de El médico de su honra que inauguró la CNTC en 1986 (pp. 420-421) o el de Calixto Bieito de La vida es sueño, también para la CNTC, del año 2000 (pp. 476-478), que ofrecen un panorama breve pero completo de lo que supusieron esos montajes en su momento. Es de agradecer también el esfuerzo realizado por el autor de acudir a diferentes fuentes que pudieran enriquecer algunas fichas que, de otra manera, habrían resultado más pobres. Así, es una delicia poder disfrutar de los comentarios de Nipho sobre varias funciones dieciochescas en algunas de las fichas (pp. 114 y ss.), o de los de Beristáin en el Diario Pinciano (pp. 194 y ss.) en funciones de finales del XVIII, muy representativos de la sensibilidad ilustrada que predominaba entonces (por ejemplo, sobre una representación de El médico de su honra escribe Beristáin en el Diario Pinciano en 1787: «Esta es una pieza abominable, digna de que el gobierno la prohíba seriamente», p. 195).

La cantidad de datos recopilada por Adillo es riquísima, realmente impresionante, y gracias a su monografía está ahora accesible en una misma fuente, sin necesidad de andar acudiendo a varias para recabar noticias sobre las representaciones de una determinada obra de Calderón. El mismo autor insistía al inicio de la introducción en que quería indagar sobre la recepción escénica de la obra de Calde- 
rón «a través de datos concretos» (p. 9), datos de los que dispone en gran cantidad gracias al trabajo acometido en la monografía.

Sin embargo, en los pequeños apartados de conclusiones de cada capítulo, así como en las conclusiones generales del volumen, da la impresión de que el autor apenas explota esos datos que ha recopilado. Por ejemplo, en las tres páginas de conclusión del capítulo 1, referidas a 250 páginas de fichas, se echan de menos datos brutos, relativos a número de puestas en escena por obras, géneros, u otros criterios, que permitirían hacer gráficos o tablas que ilustrasen algunas de las conclusiones alcanzadas en esas tres páginas. Por ejemplo, en p. 270 se escribe: «un repertorio calderoniano tan amplio y poliédrico como el que se exhibía en las carteleras del primer siglo XVIII difícilmente podía funcionar como elemento identitario, y de ahí que la praxis teatral fuese decantando poco a poco un canon escénico mucho más limitado y cerrado, que sería el que llegase al centenario de 1881», y se echan de menos ejemplos, datos, que muestren de manera clara y precisa esta afirmación. De alguna manera, parece que podría aprovecharse más el riquísimo material recopilado.

Al tiempo, en esta conclusión se hacen afirmaciones que no son directamente extraíbles de las fichas. Por ejemplo, en p. 269 se afirma: «Si durante el Setecientos la dramaturgia calderoniana había sido el modelo del teatro popular, lo cual ocasionó su descrédito entre los clasicistas, en el Ochocientos serviría de inspiración al teatro culto, y de ahí la reivindicación y la apropiación de su escritura por parte de la generación romántica y posromántica». Las fichas en sí permiten ver qué obras de hecho se representaban y con qué frecuencia, por lo que, para llegar a esta afirmación, se están manejando otras fuentes, que no se citan. De hecho, en estas tres páginas de conclusión del capítulo 1 no se cita ningún trabajo, por lo que hay que acudir a los mencionados en la introducción general, aunque habría sido útil que se localizasen los lugares concretos que permiten extraer la información que se plantea en ellas.

Reducir la conclusión a solo tres páginas también obliga a un exceso de concisión y a dar cosas por supuestas. Así, en p. 271 se escribe: «Este canon calderoniano tan limitado y por tanto tan repetitivo difícilmente podía competir con los espectáculos más populares y de más éxito cuando el Gobierno central puso fin a los monopolios y se reguló por decreto la liberalización del mercado teatral». Pero no se añade nada más al respecto, y cabe preguntarse: ¿cuándo tuvo lugar ese fin de los monopolios? ¿En qué consistió esa liberalización del mercado teatral? Solo más adelante, en p. 273, en un nuevo capítulo, se indica al menos la fecha: 1847.

En todo caso, las conclusiones nos enfrentan a situaciones de enjundia, como la paradoja de que «En este contexto histórico la frecuencia de representación del teatro de Calderón acabó siendo inversamente proporcional al poder simbólico que adquirieron determinadas puestas en escena de sus obras cuando su presencia sobre las tablas se fue haciendo menos común» (p. 270). Paradoja que, como indicamos, también se refleja en el libro, pues aumenta proporcionalmente el grado de análisis a medida que se reduce la presencia de Calderón sobre las tablas. 
Las pautas apreciadas en este primer capítulo se mantienen en los demás. En las conclusiones de cada uno de ellos se echan de menos análisis que tengan más en cuenta la generosa cantidad de datos contenidos en las fichas, al tiempo que se tratan de manera muy sucinta cuestiones relativas al campo teatral o al valor simbólico de Calderón sin que se remita a bibliografía secundaria que permita ahondar en esos aspectos. Así, en la conclusión del capítulo 2 apunta Adillo que «según avanzaba el primer cuarto del siglo XX determinados agentes del campo teatral, con Valle Inclán a la cabeza, tomaron también a nuestro autor como chivo expiatorio en sus ataques contra un gremio del espectáculo en el cual habían tratado de integrarse pero del que ahora renegaban». Cabría ilustrar y explicar afirmaciones como estas, cuando además Valle-Inclán echó mano del teatro del Siglo de Oro para reivindicar su apuesta por el esperpento².

Una situación similar encontramos en las catorce páginas de conclusiones generales, en las que solo se citan tres trabajos (todos ellos en p. 599), a pesar de que en ellas se ofrece una importante cantidad de informaciones, cuyas fuentes habrían debido indicarse de manera concreta, sin necesidad de acudir a las fuentes generales apuntadas en la introducción. En estas páginas se vuelven a tratar aspectos relativos a la creación de un campo teatral partiendo de la figura de Calderón y la representación de sus obras, así como sobre el proceso de construcción nacional y su relación con el poeta. Las páginas 599-604 exploran «la evolución del canon escénico del poeta madrileño a lo largo de estos trescientos años por géneros y por títulos concretos» (p. 600), es decir, se refieren a los elementos directamente extraíbles de los datos compilados en el catálogo. Sin embargo, de nuevo se echan en falta datos concretos, números: el autor recurre a generalizaciones, siempre interesantes, pero que quizá se podrían haber ilustrado a través de datos, tablas o gráficos. Solo en algunos casos sí aporta porcentajes, como al indicar que «con la aceptación por parte del público y de los cómicos de las piezas de Moratín y otros dramaturgos neoclásicos [...] continuó menguando la presencia de Calderón dentro de la cartelera, hasta reducirla del 25\% del total de títulos en la primera mitad del siglo XVIII al 5\% en esta primera década del Ochocientos» (p. 601), pero las cuantificaciones no van mucho más allá. En todo caso, resultan unas páginas interesantísimas para constatar cómo el Calderón serio que todavía hoy prevalece en el imaginario cultural español es básicamente un constructo del siglo XIX, pues «acaso por la preferencia del Romanticismo por los asuntos graves en esta etapa por primera vez las piezas serias [...] empezaron a superar en número de representaciones a las cómicas» (p. 601). Dicho de otra manera, hasta esa década de los años 30 del siglo XIX el Calderón que se escenificaba era fundamentalmente el cómico, y obras hoy olvidadas como También hay duelo en las damas o Afectos de odio y amor eran mucho más frecuentes sobre las tablas que La vida es sueño o El alcalde de Zalamea.

2. Para Valle, la «reteatralización» de la escena española consistía en recuperar las virtudes del teatro clásico español y en aprender las del cine moderno. De acuerdo con él, el teatro ha de ser como «El nuestro, como ha sido siempre: un teatro de escenarios. [...] Ahí está nuestro teatro clásico, teatro nacional, donde los autores no hacen más que eso: llevar la acción sin relatos a través de muchos escenarios» (Ramón María del Valle-Inclán, Entrevistas, ed. Joaquín del Valle-Inclán, Madrid, Alianza, 2000, pp. 419-420). 
El material compilado en esas fichas por Sergio Adillo constituye la gran aportación de esta monografía, por todo el caudal de información que proporcionan, que podrá ser explotado desde múltiples perspectivas por los investigadores interesados. Sin embargo, tal y como son presentadas, las fichas ven limitada su utilidad, ya que al libro le falta un elemento fundamental en un trabajo de estas características: índices. La monografía solo presenta el de contenidos, pero carece de un imprescindible índice de títulos, así como de otros posibles como lugares de representación, compañías o actores. Así, quien desee conocer cuántas puestas en escena existen de El astrólogo fingido o de cualquier otra pieza de Calderón durante el período analizado, tendrá que rastrear el libro entero. Quizá esta ausencia de índices se deba a una -esperamos que cercana- puesta a disposición de los investigadores de una base de datos en línea, a la manera de CATCOM, por ejemplo, que recoja todos los datos vertidos en la monografía y permita su rápida consulta a través de diferentes criterios de búsqueda, herramienta que resultaría fundamental para los investigadores y que podría actualizarse con otras representaciones que hubiesen podido pasarle desapercibidas a Adillo o que el propio autor pudiese aportar en años próximos.

Es posible que la ausencia de índices, así como la brevedad de los análisis que se incluyen tras los capítulos, se deba al paso de la tesis de doctorado al formato libro, pues hay elementos que parecen haberse quedado por el camino. Así, en la introducción del capítulo 4 (1939-1981) encontramos una inconsistencia que quizá sea resultado de este cambio de formato, pues escribe Adillo en p. 326: «Como en el capítulo anterior, aquí la división en epígrafes también responderá a un criterio mixto, cronológico y temático, de manera que he dedicado los dos primeros a la etapa que va desde el final de la Guerra Civil hasta principios de los años sesenta, durante la cual la presencia de nuestro dramaturgo en las carteleras fue muy intensa, y el último al período siguiente, en el que ocurrió justo lo contrario». Sin embargo, ni el capítulo anterior estaba subdividido en epígrafes, ni tampoco lo está este. De hecho, los capítulos 2, 3, 4 y 5 presentan en su ordenación la anomalía de que saltan del punto 0 al 2 y del 2 al 4 , sin que haya ni un punto 1 ni un punto 3 , resultado probablemente de suprimir epígrafes de la tesis, sin que en la monografía se reajustase la numeración adecuadamente. El plan del capítulo que se presenta en las líneas citadas tampoco parece respetarse, pues el apartado siguiente se centra en la inclusión de las fichas de espectáculos, como en capítulos anteriores, sin dividirse a partir de criterios temáticos, y a continuación se incluye una conclusión, particularmente breve en este caso, pues solo abarca dos páginas. Quizá por este mismo paso de la tesis al libro, de las numerosísimas entradas que se aprietan en las impresionantes 61 páginas de bibliografía, gran parte, de hecho, no se cita en la monografía, quizá por haberse suprimido o sintetizado los lugares en que se hacía.

A falta de los índices que facilitasen la consulta puntual del libro, sí debe destacarse que la disposición de las fichas en el formato libro permite recibir la información de una manera que no sería posible en una base de datos en línea e ir saltando de ficha en ficha a lo largo de los años. Uno puede encontrarse así con la paradoja de que en el mismo 1938 La vida es sueño fuese representada por la Compañía de la CNT en Madrid y por el Teatro Nacional de la Falange Española Tradicionalista y 
de las JONS en Burgos (p. 319), con Francisco Rabal en el papel de Segismundo (p. 361) o con un curioso montaje de El alcalde de Zalamea de 1955 en Almagro en el que diferentes dramaturgos españoles (Buero Vallejo, Luca de Tena...) encarnan a los personajes del texto de Calderón, aunque el propio Adillo duda si esta representación llegó a tener lugar (p. 362).

En suma, la presente monografía de Sergio Adillo resulta una aportación fundamental a los estudios calderonianos, pues permite el acceso en una sola fuente a un material valiosísimo recopilado de lugares diferentes y que muestra cómo fue la presencia del teatro calderoniano sobre las tablas desde 1715 hasta 2015. La falta de índices dificulta, sin embargo, la consulta del libro, aunque cabe esperar que el volcado de todos los datos recopilados por Adillo en una base de datos se convierta en una herramienta imprescindible para los interesados en el teatro de Calderón, que podrían servirse del enorme trabajo de Adillo para afrontar estudios de recepción desde múltiples perspectivas. 